\title{
Fx Healthy Physical
}

\author{
H.Mohamed Masood ${ }^{1}$ and J.Abalin Luther ${ }^{2}$ R.Kejapriya ${ }^{3}$ \\ ${ }^{1}$ Department of Computer Application, Francis Xavier Engineering College \\ ${ }^{2}$ AP,Department of Computer Application, Francis Xavier Engineering \\ College \\ ${ }^{2}$ Department of Computer Application, Francis Xavier Engineering College
}

\begin{abstract}
All are aware of the saying "health is wealth". No one in this world is perfectly alright incase of health. Each and Every is suffering from some or the other sickness. More applications are being used through the mobile devices. The study was to analyze healthy projects from the viewpoint of the planning, implementation and evaluation of the projects. The purpose was to generate knowledge about the work done in projects that can be utilized in Health physica l management.
\end{abstract}

\section{KEYWORDS}

healthy, fitness, style, styling, insert (key words)

\section{INTRODUCTION}

Lifestyle choices can include physical activity, a healthy diet, stress reduction, sleep, quitting smoking and good oral hygiene. If your habits are already healthy, make sure to maintain them. If one or more of these areas need improvement, pay some extra attention to it. For a long-term, successful change, the journey towards a healthy lifestyle should be a positive experience. Notice all small improvements; every move in a positivedirection is a step forward.Your habits have a direct impact on your well-being. For example, getting enough quality sleep will make you feel thoroughly rested, good oral hygiene will contribute to a healthy mouth, and so on. aper is organized as follows: Section II presents the proposed model of the CV system, Section III states the optimization problem formulation, Section IV expresses the model results and discussion, and Section V states the conclusion and future research work . 


\section{ArChitectural Diagram}

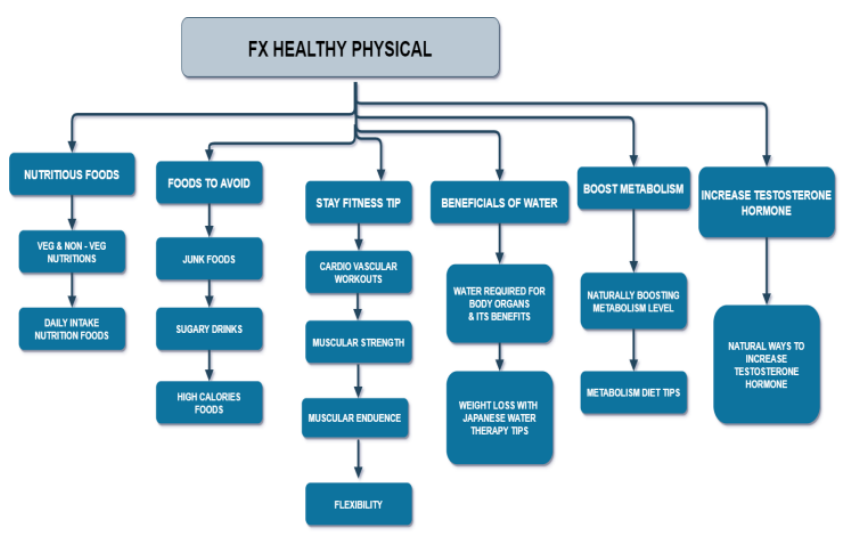

Fig-1 Architecture Diagram

\section{EXPERIMENTS AND RESULTS}

\section{Module}

\section{A. Nutritious foods}

Manufacturer will register and login to the system by using valid credentials. Then manufacturer can add the products in its database. They also generate the QR code in the products.

\section{B. Food To Avoid}

This module Mainly use of live a long day by avoiding these unwanted foods Ex: Junk Foods, Sugary Drinks, Cake \& Candy ...etc. There is no health to the human body as all of these foods are eaten .

\section{Stay Fitness Tip}

This module full focused on Fitness and Great Physique. allocate three fitness tips. fat to fit transformation, lose fat, gains weight.

\section{Beneficial of Water}

Drinking Water Helps Maintain the Balance of Body Fluids. Your body is composed of about $60 \%$ water. The functions of these bodily fluids include digestion, absorption, circulation, creation of saliva, transportation of nutrients, and maintenance of body temperature. we are includes how to reduce the body and increase the body through the Japanese method.

\section{E. Increase Testosterone Hormone}

Formula of Testosterone: $\mathrm{C} 19 \mathrm{H} 28 \mathrm{O} 2$ Testosterone is a hormone produced by the human body. It's mainly produced in men by the testicles. Testosterone affects a man's appearance and sexual development. testosterone plays a key role in the development of increased Muscle \& bone mass, growth of Body hairs. It stimulates sperm production as well as a man's sex drive. Testosterone is 
both male and female hormone. But mainly used male. Ovaries times of Female used this hormone

\section{F. Trainer}

In this Trainer Modules have more and more specification on this Website. Users can interact with the Trainers. Users can access Voice Call \& Video call with the trainers. the users can Contacts with Trainers example: email, phone no, instagram, WhatsApp etc.. The user's Any Doubts will comes with Clarify the trainers with Chat Applications. The Chat Application will provide on this website.

\section{G. Blogs}

The Blog module allows authorized users to maintain a blog. Blogs are a series of posts that are time stamped and are typically viewed by date as you would view a journal. The Trainer can Post Health based Blogs and only viewed by Users and read the daily blogs. In this Module when Trainer can post the Blogs. then Blogs will store on the database and Blogs will be displayed on User interface.

\section{Output Screen}

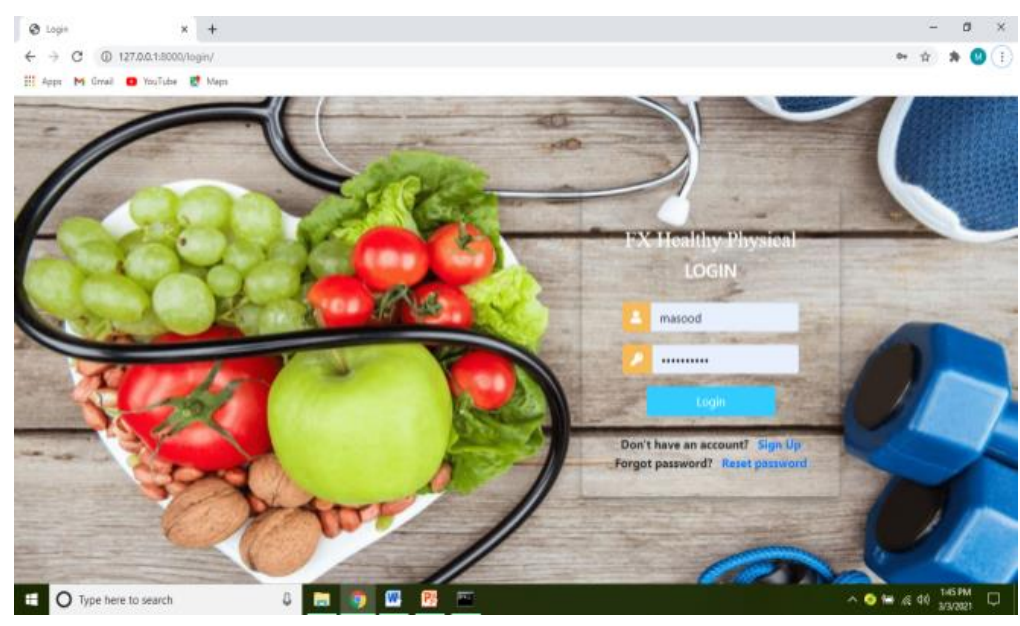

Fig- 2 Login Page

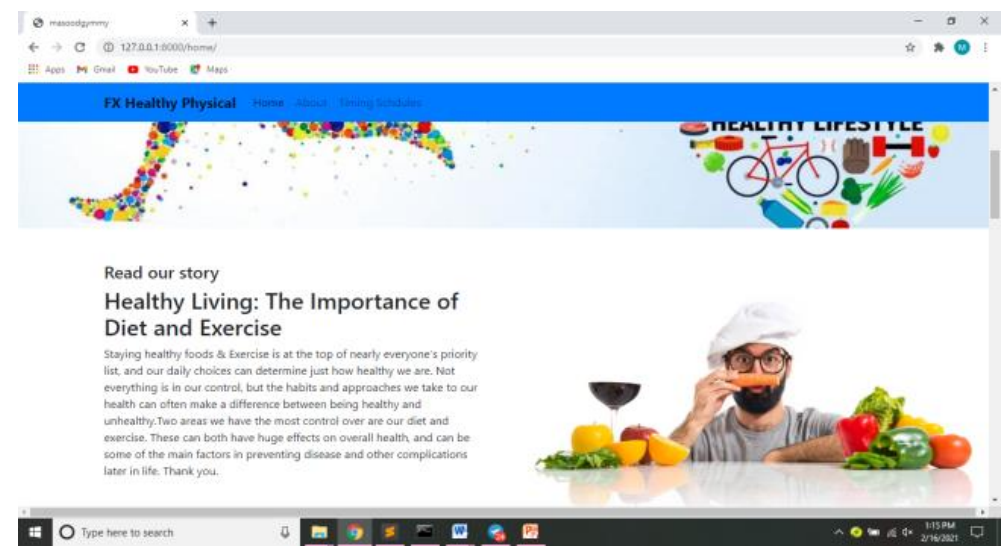

Fig-3 Register page 


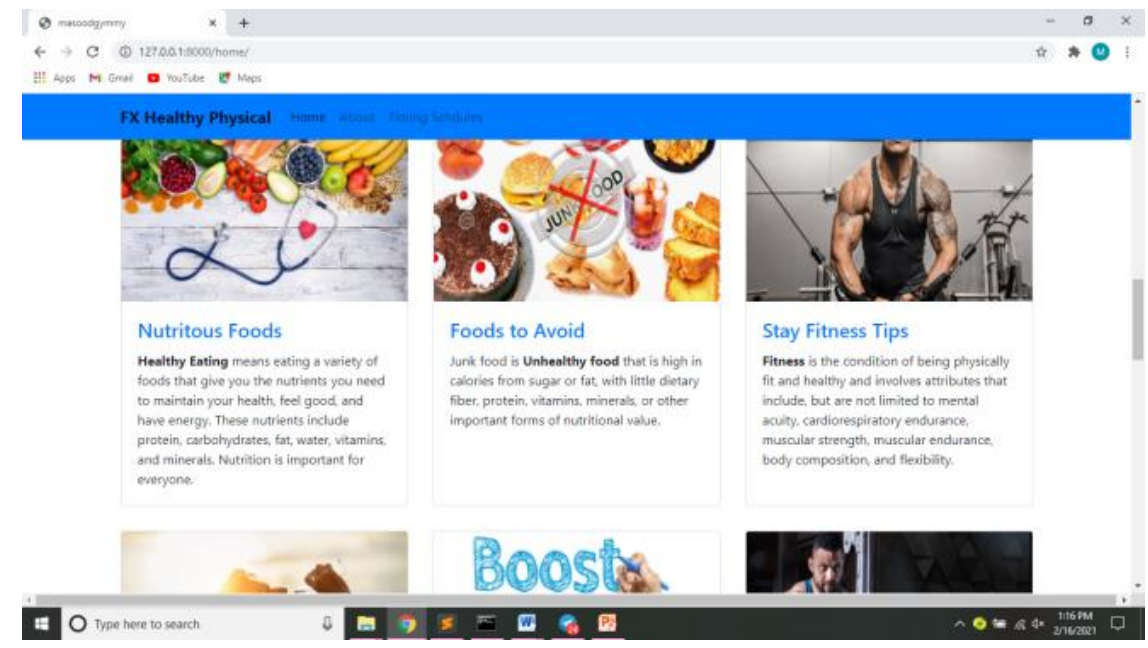

Fig-4 Home Page

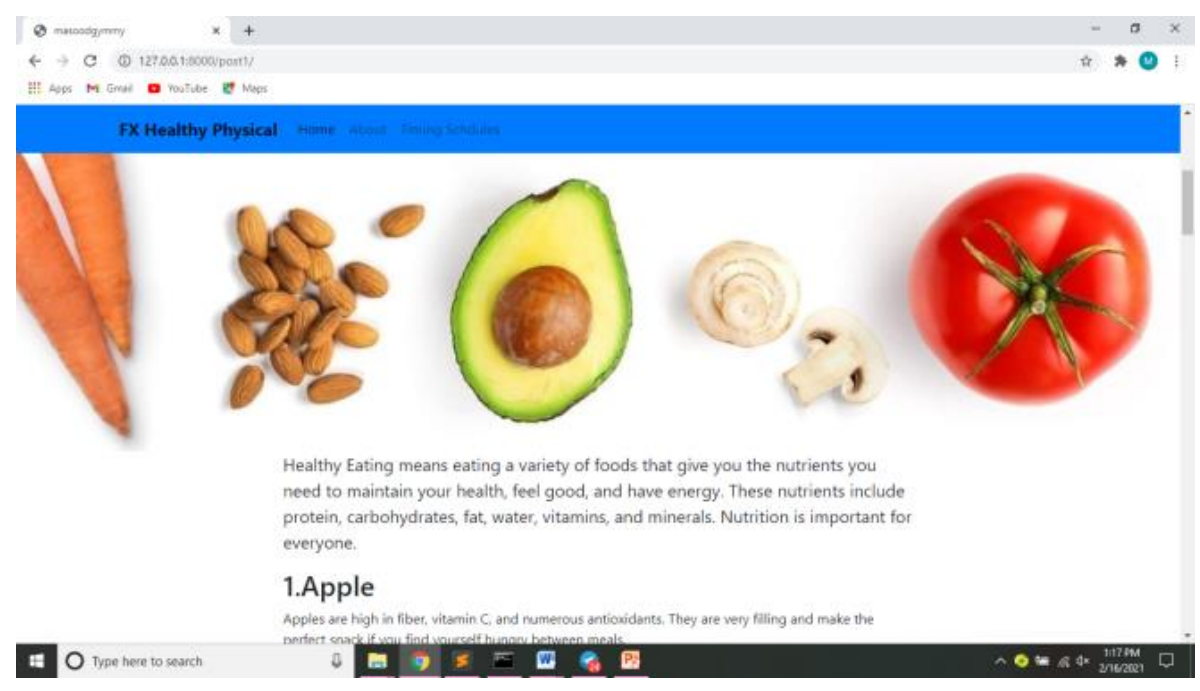

Fig-5 Nutritious foods

\section{Performance Analysis}

The existing and proposed system are analysed. The problem identified existing is system will also help in providing real time information provided by the healthcare professionals and the problem identified proposed system Including Healthy ways to Boost Metabolism and Increase the Testosterone harmone.Nearly $70 \%$ performance has been increased.

\section{CONCLUSION}

The Good nutrition is fundamental for children's current and future health, as well as their development and learning. The benefits of developing healthy dietary and lifestyle patterns from an early age onwards can positively impact on people's nutrition and health throughout their adult lives, and enhance the productivity of individuals and nations. Nutrition education is an 
important element in an overall strategy aimed at improving food security and preventing all forms of malnutrition. Schools (from pre-school to secondary) are ideal settings for promoting lifelong healthy eating habits and lifestyles.

\section{FUTURE ENHANCEMENT}

Physical fitness is a general state of health and well-being and, more specifically, the ability to perform aspects of sports, occupations and daily activities. Physical fitness is generally achieved through proper nutrition, moderate-vigorous physical exercise, physical activity, and sufficient rest. Before the industrial revolution, fitness was defined as the capacity to carry out the day's activities without undue fatigue. However, with automation and changes in lifestyles physical fitness is now considered a measure of the body's ability to function efficiently and effectively in work and leisure activities, to be healthy, to resist hypokinetic diseases, and to meet emergency situations.

\section{REFERENCE}

[1] H. Nazeran, S. Chatlapalli and R. Krishnam, "Effect of Novel Nanoscale Energy Patches on Spectral and Nonlinear Dynamic Features of Heart Rate Variability Signals in Healthy Individuals during Rest and Exercise," 2005 IEEE Engineering in Medicine and Biology 27th Annual Conference, Shanghai, 2005, pp. 5563-5567, doi: 10.1109/IEMBS.2005.1615745.

[2] G. OuYang, "Design and Implementation of Body Mass Index Calculator Based on Android Technology," 2018 2nd IEEE Advance Information Management,Communicates,Electronic and Automation Control Conference (IMCEC), Xi'an, 2018, pp. 2459-2462, doi: 10.1109/IMCEC.2018.8469304.

[3] M. Chiang, C. Wu, J. Feng, C. Fang and S. Chen, "Food Calorie and Nutrition Analysis System based on Mask R-CNN," 2019 IEEE 5th International Conference on Computer and Communications (ICCC), Chengdu, China, 2019, pp. 1721-1728, doi: 10.1109/ICCC47050.2019.9064257

[4] Gregory J. Colman \& Dhaval M. Dave" Physical Activity and Health” DOI 10.3386/w18858 ISSUE DATE February 2013

[5] Yash Jain; Hermish Gandhi; Atharva Burte; Aditya Vora," Mental and Physical Health Management System Using ML, Computer Vision and IoT Sensor Network”, 2020 4th International Conference on Electronics, Communication and Aerospace Technology (ICECA), DOI: 10.1109/ICECA49313.2020.9297447 


\section{Authors}

Ms. H.Mohamed Masood doing final year MCA in Francis Xavier Engineering College

Mrs. J. Abalin Luther is working as Assistant Professor in the Department of Computer Applications, Francis Xavier Engineering College. She is having teaching experience of 5+ years. Her area of interest is Wireless Sensor networks

Ms.R.Kejapriya doing first year MCA in Francis Xavier Engineering College
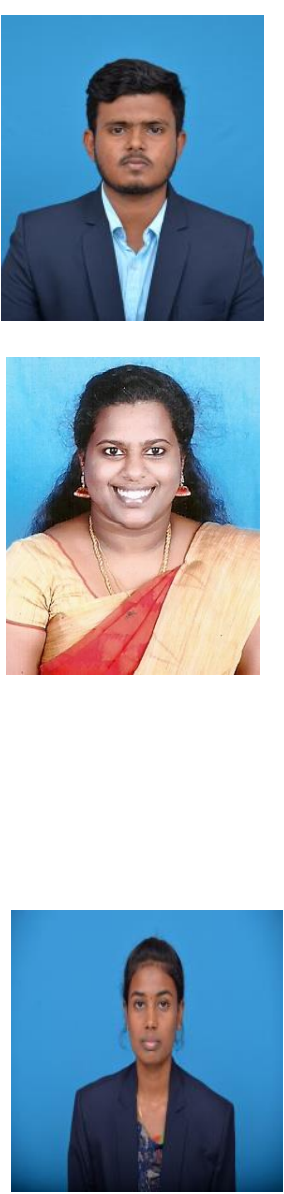